Doi: $\underline{\mathrm{dx} . \text { doi.org/10.17921/2525-5320.2016.265-266 }}$

\title{
NOVOS MODOS DE INTERAÇÕES NO PROCESSO DE ENSINO E APRENDIZAGEM ATRAVÉS DO WHATSAPP
}

\author{
Lucinalva Rosangela Panuci* - UNOPAR \\ Luciane Guimarães Batistella Bianchini* - UNOPAR
}

Palavras-chave: Interações. Aprendizagem. Aplicativo WhatsApp.

\section{INTRODUÇÃO}

Nosso estudo é resultado de uma pesquisa financiada pela CAPES, de cunho qualitativo realizada por meio do estudo de caso, de uma proposta de ensino e aprendizagem em sala de aula e extraclasse, com o aparelho Smartphone, através do aplicativo WhatsApp. Ensinar e aprender com novas tecnologias são um grande desafio, e demanda da escola a quebra de paradigmas antigos. A inclusão de NTICs transforma não só o modo de comunicar, mas também de interações do aluno com o conhecimento e relações interindividuais presentes no contexto educativo.

Investigar as possibilidades de utilização do aplicativo WhatsApp como recurso pedagógico em atividades na sala de aula e extraclasse, bem como analisar modos de interação presentes neste contexto.

\section{MATERIAL E MÉTODOS}

A metodologia adotada foi de cunho qualitativo, por meio de um estudo de caso, envolvendo 112 alunos de três escolas, sendo um colégio particular (ensino médio) e dois colégios (ensino fundamental) público.

Para analise da proposta sobre a utilização do Smartphone com o uso do aplicativo WhatsApp, junto à disciplina de Língua Portuguesa, dividimos a pesquisa em três etapas para a coleta de dados.

- Aplicação de questionário com 3 perguntas sobre a utilização dos WhatsApp pelos alunos.

\footnotetext{
* E-mail: ronucci123@gmail.com

*E-mail: luannbi@hotmail.com
} 
- Construção de regras junto ao grupo de alunos para utilização do Smartphone- WhatsApp em atividades em sala de aula e extraclasse.

- Roteiro de observação das interações do grupo através do WhatsApp.

\section{RESULTADO E DISCUSSÃO}

A inclusão do WhatsApp enquanto apoio a aprendizagem gerou inicialmente dificuldades dos alunos em relacionar-se entre si prevalecendo interações de inimizades, desinteresse com o conhecimento e solicitação intensa do professor. $\mathrm{Na}$ medida em que o professor passou a intervir explicando a proposta e construindo regras de conduta no grupo, os alunos passaram a interagir autonomamente com o conhecimento e positivamente com os colegas.

\section{CONCLUSÃO}

Concluímos que as novas tecnologias como é o caso do WhatsApp pode ser um recurso pedagógico promotor de aprendizagem, mas isso demanda tanto do professor quanto dos alunos a construção de sentidos e regras que incluam tal instrumento em sala de aula.

\section{REFERÊNCIAS}

LÉVY, P. A inteligência coletiva: por uma antropologia do ciberespaço. São Paulo: Loyola, 2007.

MORAN, J.M. Mudar a forma de ensinar e de aprender com tecnologias: transformar as aulas em pesquisa e comunicação presencial-virtual. Disponível em: http://www.eca.usp.br/prof/moran/uber.htm . Acesso em: 21 set. 2012.

KENSKI, V.M. Tecnologias e ensino presencial e a distância. São Paulo: Papirus, 2012.

UNESCO. Diretrizes de políticas para aprendizagem móvel. 2014. Disponível em: <http://unesdoc.unesco.org/images/0022/002277/227770por.pdf>. Acesso em: 10 jan. 2016. 